\title{
Self-Directed Learning in Problem-Based Learning and its Relationships with Self-Regulated Learning
}

\author{
Sofie M. M. Loyens • Joshua Magda • \\ Remy M. J. P. Rikers
}

Published online: 22 July 2008

(C) The Author(s) 2008

\begin{abstract}
This study investigated the role of self-directed learning (SDL) in problem-based learning (PBL) and examined how SDL relates to self-regulated learning (SRL). First, it is explained how SDL is implemented in PBL environments. Similarities between SDL and SRL are highlighted. However, both concepts differ on important aspects. SDL includes an additional premise of giving students a broader role in the selection and evaluation of learning materials. SDL can encompass SRL, but the opposite does not hold. Further, a review of empirical studies on SDL and SRL in PBL was conducted. Results suggested that SDL and SRL are developmental processes, that the "self" aspect is crucial, and that PBL can foster SDL. It is concluded that conceptual clarity of what SDL entails and guidance for both teachers and students can help PBL to bring forth self-directed learners.
\end{abstract}

Keywords Problem-based learning $\cdot$ Self-directed learning $\cdot$ Self-regulated learning

Self-regulated learning (SRL) is ubiquitous in research on education nowadays and it is an umbrella term for various processes such as goal setting, metacognition, and self-assessment, all of which influence learning in various ways (e.g., Boekaerts 1999; Paris and Paris 2001; Zimmerman 1989). Training programs that promote self-regulated learning have been found to be beneficial for students' learning (e.g., Mason 2004). Further, self-regulated learning is a good predictor of academic performance (e.g., Minnaert and Janssen 1999). Although it has been argued that, regardless of the instructional format, all learners are inevitably engaged in some form of self-regulation (i.e., they all plan, monitor, and evaluate their behavior to some degree, Winne 1995); some learning environments frame the development of students' selfregulatory strategies as an explicit learning outcome. An example of such an instructional format is problem-based learning (PBL). However, in PBL literature, the term self-directed learning (SDL) is employed (e.g., Schmidt 1983).

S. M. M. Loyens $(\bowtie) \cdot$ R. M. J. P. Rikers

Department of Psychology, T13-44, Erasmus University Rotterdam, Bgr. Oudlaan 55, 3062 PA Rotterdam, The Netherlands

e-mail: Loyens@fsw.eur.nl

J. Magda

Department of Human Development, University of Maryland, College Park, MD, USA 
This study investigated the role of self-directed learning in PBL and examined how SDL relates to SRL. Further, a review of empirical studies that examined SDL and SRL in PBL environments is conducted. The first part of this study is hence theoretical and explains the concept of SDL and how it is implemented in PBL. In addition, this study aims to establish conceptual clarity between SDL and SRL. The second part provides a review of the literature. To that end, several literature searches in PsycINFO, ERIC, and MEDLINE were carried out using the terms self-direct*, problem-based, and self-regulat*. The first combined search (self-directed and problem-based) provided 81 entries of which 28 were relevant for the purpose of this article. The subsequent combined search using self-direct* and self-regulat* resulted in 87 hits of which five were relevant in addition to the first literature search. Self-regulat* and problem-based provided 15 entries and five of them were included supplementary to the previous searches. Studies were included when they were carried out in a PBL setting and when SDL or SRL were variables under study. Only empirical and review articles in peer-reviewed journals and edited books were considered. Dissertations as well as conference papers were excluded from examination. Finally, references of the articles resulting from the above-mentioned searches were examined, which led to the selection of two additional relevant publications.

\section{Problem-Based Learning}

Origin

PBL was developed in the mid-1960s as a useful instructional alternative to conventional teaching. It originated in medical education and was introduced because many students in medical education could not see the relevance of first-year course material (e.g., anatomy, physiology, or biochemistry) to their future professions as medical doctors. Students were looking forward to working with real patients and trying to solve their problems, which typically does not happen until the internships. This led to disappointment among students as well as difficulties with integrating subject matter of different medical disciplines (Barrows and Tamblyn 1980; Schmidt 1983).

The medical school of McMaster University in Hamilton, Canada was the first to tackle these issues and they designed an instructional format that made use of "problems" that reflected realistic medical problems that physicians encounter. However, the use of problems in education was not new since some Law and Business schools had long been using real-life problems (Barrows 1996). PBL's “creative" element was the moment at which students encountered such problems. At McMaster, students started to work with problems before they had acquired any significant knowledge of the topic at hand, which differed from the situation in Law and Business schools where problems were encountered and solved after some competence was achieved. In other words, PBL distinguished itself by making problems a starting point of the learning process. It is assumed that Donald Woods of McMaster University Medical School was the first to use the term "problem-based learning" (for a detailed discussion: Savin-Baden and Major 2004). Since its origin, PBL has been implemented in numerous programs across many domains such as Law, Economics, Business Administration, social sciences, and even secondary education (Barrows 1996).

The process

In PBL, small groups of students learn collaboratively in the context of meaningful problems that describe observable phenomena or events (Schmidt 1983). On some occasions (e.g., in 
medical education), these problems originate from professional practice; in other cases, they tackle problems or events typical for a particular domain of study (Barrett 2005; Barrows 1996; Norman and Schmidt 1992; Schmidt et al. 2007). In either case, the problems need to be understood in terms of their underlying theoretical explanations. Students can garner understanding by discussing the problem with their fellow students and proposing possible explanations or solutions during the so-called tutorial meetings.

As mentioned, the problem discussion takes place before students have received other curriculum inputs; therefore, their prior knowledge is all-important. Since their prior knowledge of the problem at hand is limited, this discussion leads students to formulate issues for further SDL. Subsequently, students spend time selecting and studying literature that is relevant to the issues generated, as well as planning and monitoring the study activities that need to be carried out before the next tutorial meeting takes place. After this period of self-study, students share and critically evaluate their findings, elaborate on knowledge acquired, and have an opportunity to correct misconceptions (Hmelo-Silver 2004; Schmidt 1983). The whole process takes place under the guidance of a tutor (sometimes also called facilitator or coach) who stimulates the discussion, provides students with relevant content information if needed, evaluates the progress, and monitors the extent to which each group member contributes to the group's work. Tutorial meetings are held twice a week and last 2 or $3 \mathrm{~h}$ each (Schmidt et al. 2007).

Goals

Like most educational innovations, PBL faced heightened scrutiny when it was introduced into educational practice. Since that time, proponents of PBL have been challenged to clearly articulate its goals. PBL aims to help students to (a) construct an extensive and flexible knowledge base, (b) become effective collaborators, (c) develop effective problem-solving skills, (d) become intrinsically motivated to learn, and (e) develop SDL skills (Barrows 1984, 1985, 1986; Barrows and Tamblyn 1980; Norman and Schmidt 1992). A discussion about whether PBL has succeeded in achieving its goals is beyond the scope of this article. Findings with respect to SDL will be discussed in the review section and, regarding PBL's other goals, see Norman and Schmidt (1992) and Hmelo-Silver (2004) for a detailed discussion. Here, we highlight the goals that the instructional format of PBL aims to achieve.

An extensive and flexible knowledge base should enable students to retrieve and use information when needed. The activation of prior knowledge during the problem discussion in the tutorial group sets the stage for the to-be-learned information, which facilitates elaboration and increases retention. By working together in tutorial groups, students develop interpersonal skills and learn how to become good collaborators. They learn to contribute to the group discussion in an open and clear way, to come to an agreement about the learning issues and the answers to these issues, and to resolve possible inconsistencies in their findings (Hmelo-Silver 2004). Since the problem is the starting point in the PBL process, students learn to develop their problem-solving skills.

In medical education, students mostly encounter problems that need to be solved (e.g., state a diagnosis and subsequent treatment based on the patient information in the problem). In other domains, however, the problem does not need necessarily or cannot as such be solved, and then the primary goal is to explain or understand the problem in terms of its underlying mechanisms. Either way, students learn how to analyze the problem at hand, assess the importance of various pieces of information, and decide which information will be used to understand, explain, or solve the problem and plan subsequent (study) actions.

The fourth goal of PBL is fostering students' intrinsic motivation to learn. Working on problems is believed to be engaging and interesting for students since they encounter realistic 
situations, sometimes (e.g., in medical education) related to their future professional practice. Besides working on personally meaningful tasks, it is also believed that the control students have over their learning is motivating as well (Bandura 1997). The notion of control introduces the final goal of PBL, namely to develop skills for SDL, which is the focus of this paper. In the next section, it will be explained what SDL implies and how PBL fosters the development of SDL. Further, we explore how SDL relates to SRL and whether these concepts are interchangeable.

\section{Self-Directed Learning}

It has been argued that the notion of SDL goes back to the existentialist perspective, which postulates individual freedom, responsibility, and personal views (Savin-Baden and Major 2004). In the context of learning, this implied that "learning should empower a student to become a free, mature, and authentic self" (Savin-Baden and Major 2004, p. 14). A detailed discussion of the epistemological origins of PBL can be found in Savin-Baden and Major (2004). Also, SDL has been widely reported in adult education. Knowles (1975, p. 18) defines SDL as "a process in which individuals take the initiative, with or without the help from others, in diagnosing their learning needs, formulating goals, identifying human and material resources, choosing and implementing appropriate learning strategies, and evaluating learning outcomes."

According to Knowles (1975, 1990), learning does not take place in isolation but in association with others such as teachers, tutors, and peers. Therefore, learning can be placed on a continuum, ranging from teacher or other oriented at one end to self-directed at the other end. When shifting from one end the other, the amount of control over learning changes as well as the amount of freedom to evaluate learning needs, to decide on the content of one's learning issues, and to implement learning strategies to unravel one's learning issues (Fisher et al. 2001). Although the area of adult education has focused on dimensions of SDL (e.g., sociological, pedagogical, and psychological) and interactions between those dimensions (Evensen 2000), studies in educational settings such as PBL depart from the learner. In these studies, SDL is investigated in terms of the degree of control learners have as well as abilities and skills they need to display in order to be effective.

\section{SDL in PBL}

In the PBL literature, SDL refers to "the preparedness of a student to engage in learning activities defined by him- or herself, rather than by a teacher" (Schmidt 2000, p. 243). This definition refers both to a motivational, volitional component of having the willingness to engage in those learning activities, as well as the ability to do so. The theoretical framework of Candy (1991), stemming from adult education, has often been used to describe and study SDL. For example, Blumberg (2000) used this model to evaluate the evidence that problembased learners are self-directed learners. Candy (1991) considers SDL as a goal as well as a process and he defines four dimensions of SDL: personal autonomy, self-management in learning, the independent pursuit of learning, and the learner control of instruction.

Personal autonomy refers to a personal characteristic or attribute of students and implies independence, freedom of choice, and rational reflection. According to Candy (1991), personal autonomy represents one of the principal goals of education in all settings and all ages. Selfmanagement is the willingness as well as the ability of the learner to manage his or her own learning. Although personal autonomy can be considered to be an overall disposition, selfmanagement refers to the exercise of autonomy in learning. Candy further distinguishes 
learner control from the independent pursuit of learning. The first deals with control over aspects of the instructional situation, while the latter implies autodidaxy and concerns learning outside formal educational settings (Candy 1991; Kreber 1998). Having outlined the dimensions of SDL, how does this apply to the PBL context?

According to Blumberg (2000), Candy's SDL model can be applied to the learning process itself, the learning strategies students employ, as well as to the performance outcomes of SDL in the PBL context. With respect to the learning process in PBL, students need to assess their learning issues based on the analysis of the problem discussed in the tutorial group. These learning issues, formulated as questions, comprise what needs to be looked up in the literature and subsequently be studied, to gain a better understanding of the problem. Given their prior knowledge of the study topic, students have to decide independently how detailed and extensive their self-study should be. Essentially, "students are free to pursue whatever literature resources they deem interesting in light of the problem" (Schmidt 2000, p. 243).

However, literature resources that are considered relevant need to be critically evaluated. Further, students need to carefully plan their self-study activities in order to be optimally prepared for the next tutorial meeting, which requires effective time management. These activities put students effectively in charge of their own learning since they also need to evaluate after the tutorial meeting whether their study activities as well as those of their fellow students have been sufficient to meet their learning needs (Schmidt 2000). This aspect of selfevaluation is a crucial component of SDL (Blumberg 2000; Candy 1991). In sum, SDL entails the ability to assess learning needs, effective planning, and time management, a critical evaluation of the literature resources, as well as a critical evaluation of their own SDL skills. Personal autonomy, self-management, and learner control hence clearly play a role in the PBL learning process.

Candy's (1991) SDL model can also be applied to learning strategies. Learning strategies refer to the way students process the subject matter. A distinction is made between deep and surface level of processing. Deep-level processing is aimed at seeking meaning in the subject matter, while in surface learning the reproduction of the content is the first matter of importance. Deep-level processing goes hand in hand with study activities such as elaboration and looking for patterns and underlying principles. Students who adopt a surface-level processing strategy will more likely engage in rehearsal and memorization (e.g., Entwistle and Peterson 2004). The link with SDL lies in the fact that, in an educational setting, learning is often tuned to assessment and teacher demands. The emphasis of classroom activity is mostly on the teacher and students can come to see assessments and teachers in these kinds of educational settings as controlling. In that case, responsibility, ownership, and self-direction are undermined (Blumberg 2000). Learning environments that foster SDL such as PBL are believed to promote deep-level processing because learners have the freedom to choose what they learn and how they learn it (Candy 1991). Learner control is therefore crucial in terms of effective learning strategies. Finally, Candy (1991) highlights the importance of SDL for performance outcomes, both in the short and the long term. This will be discussed in greater detail in the section on SDL and SRL research in PBL.

Hmelo and Lin (2000) also argued that specific PBL features support the development of SDL. The student-centered nature of PBL, the fact that students start working on a problem before they have received other curriculum inputs, the identification of their knowledge deficits, the generation of their own learning issues, students' individual study, the critical evaluation of the literature resources, the application of the new knowledge to the problem, and the critical and collaborative reflection on their SDL skills are all crucial features that foster SDL. Especially with respect to the independent literature search, students have the opportunity to develop their information-seeking skills, which prepares them to become 
flexible and adaptive learners. Further, Hmelo and Lin (2000) emphasize the reflection element in PBL. If a student cannot understand or solve a problem with the literature resources he or she found, additional learning issues need to be formulated and the process of literature search and critical evaluation is reiterated. This reflection on students' SDL skills happens individually when a student notices that his or her study activities were insufficient and collaboratively when students, after hearing each other's input in tutorial meetings, realize that their literature resources do not (fully) cover the subject to be studied.

Two notes: lifelong learning and individual unguided learning

Having outlined what SDL is and how it is fostered in PBL environments, it should be noted here that SDL is often bracketed together with lifelong learning (e.g., Miflin et al. 2000). Although both concepts start with the student's intrinsic motivation to learn, they are not the same (Schmidt 2000). Greveson and Spencer (2005) consider SDL to be a prerequisite for lifelong learning, while Candy (1991) describes SDL and lifelong learning as having a reciprocal relationship. Candy subsumes lifelong learning under one of four dimensions of SDL. Specifically, SDL is the principal activity in the independent pursuit of learning, while the goal of lifelong learning is "equipping people with skills and competencies to continue their own 'self-education' beyond the end of formal schooling" (Candy 1991, p. 15). Therefore, SDL can be considered both a means and end to lifelong learning.

Another note that should be made while discussing SDL in a PBL context is that this concept is not similar to individual, unguided learning. Candy (1991) argued that the term self-direction can be misleading because the individual should not be evaluated above the collective. In his view, learning is not an individual affair, but it implies relationships with others. In PBL, students work together in groups and they formulate their learning needs collectively. A tutor scaffolds this process and makes sure that the course designer's intended subject matter is covered. Thus, SDL in the PBL context does not imply "radical" self-direction in the sense that there is no influence on or interference whatsoever with what students learn and how they do this. PBL supports students to some extent in finding their way (Schmidt 2000). It is acknowledged that different interpretations of SDL in PBL exist (Miflin et al. 2000). For example, in some implementations of PBL, the role allocated to the tutor can be better described by "the reticent member of the tutorial group" instead of the facilitator (Miflin 2004). Also, students might consider SDL equal to "lack of support" in some PBL curricula (Dornan et al. 2007) or "self-teaching" (Shanley 2007). However, the previous sections aimed to clarify that SDL in PBL does not entail "do-ityourself education."

\section{Linking Self-directed and Self-Regulated Learning}

SRL

As noted, self-regulated learning (SRL) is an umbrella term for various processes. In its most concrete sense, SRL is a specific form of learning that can be distinguished from learning that is externally regulated (Boekaerts and Cascallar 2006). This implies that learners have control over their own learning and that they can direct cognition and motivation to achieve a specific learning goal. SRL can be investigated from several perspectives, emphasizing, for example, volitional, cognitive, and sociocultural aspects. However, four key elements or assumptions can be distinguished in theories or models of SRL. First, SRL implies active engagement in 
one's learning process. During this process, learners set goals, monitor their thoughts, feelings, and actions, and adjust them if needed. Second, SRL models start from the idea that students are able to make use of standards to direct their learning and to set their own goals (i.e., they have control). SRL operates within the biological, developmental, contextual, and individual "boundaries" of the learner, but students can be trained to extend their metacognitive knowledge base and hence to become more effective self-regulated learners. Third, learning behavior is goal-directed rather than random. Finally, SRL is viewed as a mediating variable between variables on the personal or situational level and achievement (Ainley and Patrick 2006; Boekaerts and Corno 2005; Pintrich 2004).

These four assumptions clearly come to the fore when analyzing the SRL process: Selfregulated learners will carefully plan their learning activities before they initiate a specific task. The starting point is to analyze the task at hand and to determine the task (e.g., what is the task about?) and personal features (e.g., what knowledge can I apply? Do I find the task interesting?). Subsequently, goals are set and plans are devised in order to enact tactics and strategies. During those steps, self-regulated learners reflect on the steps that were taken, monitor their progress, and change their plans accordingly (Winne and Hadwin 1998). SRL processes involve metacognition, intrinsic motivation, affective factors, and strategic action (Pintrich 2004; Winne and Perry 2000), which happen within a specific context (e.g., classroom). Those elements nicely concur with Zimmerman's (1989) definition of SRL: "Students can be described as self-regulated to the degree that they are metacognitively, motivationally, and behaviorally active participants in their own learning process" (p. 329).

Both learner and learning environment characteristics can influence the SRL process. The learner's choice of goals is an important determiner of SRL (Zimmerman 2000) and goals can compete with one another. For example, the pursuit of a task goal of mastering a study topic can be hindered by a social goal of having fun with friends (e.g., Pintrich 2003). Another key element in SRL is students' interest. When students encounter a specific task, interest defines the level of connection between student and task (Ainley and Patrick 2006). With respect to the learning environment, the clarity and pace of instruction, the amount of structure provided, and the degree of control students experience with respect to their learning are important for students' SRL activities. Further, certain teacher characteristics such as enthusiasm, humor, and fairness, as well as teacher expectations about students' capacities were significantly related to SRL (Boekaerts and Cascallar 2006).

\section{Similarities between SRL and SDL}

Very few literature sources describe SDL and SRL as distinct concepts. This might be explained by the different traditions of both concepts. However, Zimmerman and Lebeau (2000) argue that the definitions of SDL in the PBL context are highly similar to what other literatures have termed SRL. Overall, both SDL and SRL involve active engagement and goal-directed behavior. Both entail goal setting and task analysis, implementation of the plan that was constructed, and self-evaluation of the learning process. In the SRL literature, these concepts are labeled as forethought, performance or volitional control, and self-reflection (Zimmerman 1998; Zimmerman and Lebeau 2000). Similarly, SRL and SDL are similar in that they both activate metacognitive skills. Metacognitive awareness is involved in all steps that precede the actual study activities (i.e., goal setting and setting up a plan to achieve them), as well as the evaluation of those activities afterwards. Students need to ask themselves at several points in time what they do and do not understand (Hmelo-Silver 2004). 
Further, definitions of SDL and SRL both emphasize intrinsic motivation as a crucial component. Without this volitional aspect, it is not likely that learners will be successful in SDL or SRL. Notwithstanding, relations with motivation are stressed most prominently in SRL studies. SRL literature strongly focuses on interest and motivational constructs such as selfefficacy and has studied how motivation can sustain SRL (e.g., Pintrich 1999). In the SDL literature, the role of motivation is certainly deemed important, but research studies pinpointing specific aspects of motivation are lacking. Finally, despite the different traditions and terminology within SDL and SRL, both concepts clearly share significant overlap. In fact, both terms have been used synonymously in previous research because of their similarities (Evensen et al. 2001).

\section{Differences between SDL and SRL}

In order to understand the differences between SDL and SRL, a distinction needs to be made between both concepts as design features of the learning environment versus learner characteristics (i.e., activities or processes that the learner substantiates). SDL pertains to both, whereas SRL is usually described as a favorable learner characteristic. This can be explained in terms of the different backgrounds of SDL and SRL research. The adult education roots of SDL give this concept a history in learning outside school environments. The independent pursuit of learning dimension in Candy's (1991) model clearly exemplifies this. SRL, on the other hand, has been studied within school learning. Therefore, SDL has a tradition of being conceptualized as a design feature of the learning environment (sometimes SDL is even called a method of instruction in adult education literature, e.g., Fisher et al. 2001) as well as a process of learning. Naturally, SDL environments are designed to foster self-direction that students will carry into subsequent learning situations.

In sum, the concept of SDL is broader than SRL. SDL as a design feature of the learning environment stresses students' freedom in the pursuit of their learning. In PBL, students are given the freedom to select and critically evaluate their own literature resources to achieve these goals. It could be argued that self-regulated learners in other kinds of classrooms could do the same, but some learning environments afford more freedom to direct and control learning than others. As mentioned, learning is often centered on assessment and teacher demands. However, if the learning environment does not leave room for, at least, some elements of control in this respect, the process of finding your own literature resources becomes unlikely. In this sense, SDL includes an additional premise of giving students a broader role in the selection of what will be learned and critical evaluation of the learning materials that were selected.

As such, a closer examination of both SRL and SDL as learning processes brings the issue of student control over the learning task to the fore. Clearly, both SDL and SRL carry an element of student control. However, the degree of control the learner has, specifically at the beginning of the learning process when the learning task is defined, differs in SDL and SRL. In SDL, the learning task is always defined by the learner. A self-directed learner should be able to define what needs to be learned (Candy 1991). This is not necessarily an individual process since, in PBL, learning issues are formulated collaboratively. But the learner is the initiator of the learning task. In SRL, the learning task can be generated by the teacher. Students can to varying degrees freely select their personal learning strategies and engage in SRL activities on an assignment that is given by the teacher. In this sense, SDL can encompass SRL, but the opposite does not hold. SRL seems more concerned with the subsequent steps in the learning process such as learning goals and strategies, while SDL clearly provides a crucial role for the learner at the outset of the learning task. 


\section{Review of Studies Investigating SDL and SRL in PBL}

Various studies have considered SDL and SRL in the PBL context. Most studies have been conducted within medical education, which is not surprising given the roots of PBL. By far, most studies investigated SDL in the PBL context. Only three studies were found that examined SRL and PBL. For example, a review study by Blumberg (2000) examined whether PBL students are self-directed learners. The study was organized along three dimensions: the learning process, learning strategies, and learning outcomes. Further, a distinction was made as to whether SDL was investigated as a holistic concept or as component skills (e.g., define what to learn or planning). The type of data (self-report, faculty report, or performance) was identified for each study as well.

In the studies reported in Blumberg's (2000) review, components skills of SDL were examined by students' use of self-generated learning issues, self-reported time spent on independent study, use of literature resources, use of the library, and students' level of critical evaluation of literature resources. The results of this review highlighted that PBL fosters the development of SDL according to both students and faculty. Further, students in PBL frequently used library resources in a self-directed and critical way. Assessment of students' learning strategies revealed that students in PBL rated themselves higher on deep-level processing compared to students in a conventional curriculum. Finally, PBL students reported a learning curve in their SDL abilities. More specifically, the ability to define what needs to be learned, accessing the learning material, and actively studying the materials develops within PBL students. However, the main conclusion of Blumberg's (2000) study was that "we have a need for much more research to better understand how, when, and why PBL fosters the development of SDL" (p.225).

The next sections will focus on the studies investigating SDL and SRL in PBL published after Blumberg's review in 2000 along with three studies, published before 2000, that were not part of Blumberg's review (i.e., Dolmans and Schmidt 1994; Shin et al. 1993; van den Hurk et al. 1999). The studies on SDL in PBL are categorized based on the components of SDL that were central in the respective studies: learning issues, time planning and self-monitoring, and influences on information-seeking behavior. Two studies examined PBL graduates in the light of SDL. Four studies dealt with the question whether PBL fosters the development of SDL. Further, some studies did not explicitly focus on SDL but mapped students' perceptions in PBL environments in general. They are mentioned in this review to the extent that SDL was the object of investigation. Another study examined the influence of the tutorial group size on SDL. Finally, three studies were found that scrutinized SRL in PBL.

\section{Learning issues}

Learning issues constitute an important part of the SDL process in PBL as mentioned before. A study by van den Hurk et al. (1999) dealt with students' commitment to and use of the learning issues (i.e., learning issues treated as strict or as general guidelines) and investigated relationships among this commitment, self-reported individual study time, and students' performance on knowledge tests. Students enrolled in the first to fourth year were questioned and results showed a change in students' commitment to the learning issues during their program. First-year students perceived the learning issues as strict and study accordingly, while senior students also studied beyond the learning issues. Those students who engaged in study activities beyond the learning issues reported more individual study time and performed better on the knowledge tests. It is concluded that PBL students become better self-directed learners throughout their program (van den Hurk et al. 1999). 
An experimental approach was used to test the influence of the self-generation of learning issues in a study by Verkoeijen et al. (2006). Two student groups in PBL were compared on the number of literature resources used, self-study time, and time spent on sharing and discussing literature findings in the tutorial group. One student group received a problem in which the learning issues were incorporated, whereas the other group received the same problem, but they had to generate learning issues by themselves. Self-generation of the learning issues had a positive effect on the number of studied learning materials, self-study time, and time allocated to report the studied literature. These findings confirmed the assumption that the self-generation of learning issues is crucial and beneficial for students' learning process (Verkoeijen et al. 2006).

Time planning and self-monitoring

Van den Hurk (2006) questioned students about their capabilities to plan their self-study time and to monitor their study activities. In the studied PBL curriculum, students took two courses simultaneously within a 7-week time period. Relations of time planning and self-monitoring with self-study time, number of times they did not prepare for a tutorial group during the course, and performance on both course tests were tested. It should be noted that van den Hurk used the term SRL in her article. However, in describing the SRL process in PBL, references are made to the SDL literature in PBL and, therefore, this study is discussed here. Overall, mean scores of time planning and self-monitoring were low. However, students who scored high on time planning and self-monitoring reported less study time (i.e., were more efficient). No significant difference was found for the four groups (i.e., very low, low, high, and very high scoring on time planning and self-monitoring) for tutorial group preparation. Relations between time planning and course test grades were nonsignificant, while self-monitoring showed a significant relation with performance. Thus, although students do not frequently engage in time planning and self-monitoring, these SDL components contributed to efficient use of selfstudy time. In addition, self-monitoring seemed beneficial for academic achievement.

Information-seeking behavior

Dolmans and Schmidt $(1994,2000)$ looked into the influences on students' decisions of what to study. More specifically, they asked students of four different curriculum years whether tutorial group discussion, assessment, course objectives, lectures, the tutor, and reference literature mentioned in the course book had an impact on their information-seeking behavior. Different outcomes were found for different curriculum years. For first-year students, decisive factors that guide their study were reference literature and content covered in course tests and lectures. However, for senior students, the influence of these factors decreased. Those students reported to rely more on the discussion in the tutorial group. The scaffolding that the PBL environment provides in terms of lectures, reference literature, etc. seems most important for first-year students. Again, senior students gave evidence of better SDL skills.

SDL of PBL graduates

A study of Shin et al. (1993) examined SDL as "keeping up-to-date after graduation." Graduates from a medical PBL and a medical non-PBL curriculum were compared. A questionnaire that assessed knowledge about the management of hypertension was used to determine how well they kept up to date with current clinical practice guidelines for hypertension. Significant differences between both groups were found in favor of the PBL 
group. In addition, Schmidt et al. (2006) studied whether graduates of medical PBL curricula were better prepared to respond to the challenges of professional practice than graduates of conventional curricula. Graduates needed to indicate whether they considered themselves less, more, or equally competent compared to their colleagues who were trained in another non-PBL medical program. Results showed that graduates of PBL rated themselves as having much better SDL skills compared to the control group.

\section{Does PBL foster SDL?}

Hmelo and Lin (2000) investigated whether PBL could be effective in facilitating the development of SDL. Certain learning issues (i.e., learning issues referring to data- versus hypothesis-related learning issues), learning plans (i.e., choice and use of learning resources), and information integration were scrutinized as SDL components. PBL students generated more hypothesis-related learning issues, used more as well as a wider range of resources, and integrated more information in their explanations after studying the resources compared to non-PBL students. These findings indicate that PBL fosters SDL, as did the study by Evenson (2000). Based on interview data, Evensen investigated the development of SDL of two students in a medical PBL curriculum. Students' narratives gave evidence of the development of SDL during their first semester in medical school. More specifically, both students showed development in coping with challenges regarding their expectations such as goal setting and self-efficacy beliefs, reflection on the learning process, and influences of the environment on information-seeking strategies.

Llyod-Jones and Hak (2004) reported two case studies to explore first-year students' experiences in a PBL medical curriculum during two successive cohorts. Both qualitative (participant observation, interview, and focus groups) and quantitative (surveys) methods were employed. Results of the first case study indicated that students experienced uncertainty with respect to what to learn and that they relied on their peers and given faculty resources instead of selecting resources independently. Results for the second case study were similar, indicating that the learning of the students under study was not self-directed.

Kivela and Kivela (2005) investigated students' responses to the implementation of PBL in a traditional teaching curriculum in Hong Kong. Students were questioned about their learning preferences before and after the switch to PBL. Questionnaire results showed that after implementation of PBL students preferred the lecturer's directions and guidance for their learning to a lesser extent. Instead, they relied on their own as well as on their fellow students. The reliance on fellow students for their learning decreased in the second year and, in this sense, senior students gave evidence of SDL. However, results also indicated that students still sought the teacher's approval to be sure they were on the right track and to overcome their uncertainty in their new learning environment.

Students' perceptions of SDL in PBL

In one study by Dahlgren and Dahlgren (2002), semistructured interviews about students' experiences of PBL, among which SDL, showed mixed results. Some students deemed the freedom to select one's own literature resources challenging and interesting, while others expressed feelings of uncertainty. However, senior students gave evidence of a learning curve with respect to SDL since they had gained more confidence in the process of selecting learning resources. In another study, Dornan et al. (2005) examined medical PBL students' perceptions of whether and under which conditions they could learn in a self-directed way during their internships. Students acknowledged the importance of SDL in clinical practice. 
Further, students had a clear view on what SDL entails, as the following student's comment demonstrates: "I think as long as you've got a set of learning objectives, along with some sort of agenda, then you can be self-directed" (p. 364). Further, students indicated that they needed support by teachers to become self-directed. But when guidance and support were given, students were motivated to make a plan to achieve their learning needs.

A study by Srinivasan et al. (2007) asked students by means of a questionnaire about their perceptions of PBL and case-based learning (CBL) and the advantages of each instructional format. The medical curriculum in this study had shifted from PBL to CBL, which uses a guided inquiry method. It should be noted in this respect that, in this article, PBL was defined as a discovery process in which the tutor does not guide the discussion at all. The majority of students preferred CBL. However, the few students preferring PBL felt it encouraged SDL and valued its greater opportunities for participation.

\section{Group size}

SDL can also be influenced by PBL's less obvious features. For example, Lohman and Finkelstein (2000) investigated the effects of group size on SDL. Small tutorial groups of three students, medium groups of six students, and large groups of nine students were compared. SDL was measured by Guglielmino's (1995) Self-Directed Learning Readiness Scale. Analysis of the SDL pretests and posttests demonstrated that the PBL course led to higher SDL in small and medium groups but lower SDL in large groups. In addition, medium and large groups differed significantly in SDL.

\section{SRL and PBL}

Evensen et al. (2001) investigated how students self-regulated their learning during the first semester of their medical PBL program. Six case studies were constructed. Although Evensen and colleagues used SRL and SDL as synonyms, this study was conducted within the theoretical framework of SRL. Students' responses were clustered in the following categories: the need to self-regulate, adopting strategies and attuning to the program, adopted forms of SR, labeled "stance," and learning as identity development. Students' responses to the need to self-regulate in terms of determining their own learning needs were mostly positive. SRL was equated with independent study, contrasted with study strategies such as cramming, and considered "a first step in taking control of their professional lives" (Evensen et al. 2001, p. 664).

Learning strategies were found to change by becoming attuned to the learning environment. This enabled students to make progress in achieving their learning objectives. Further, the forms of SR (i.e., stances) that students adopted evolved over time. Five possible forms of SR were identified: proactive, reactive, retroactive, interactive, and transactive. A stance is most salient in the learning strategies that students adopt, but it also influences students' planning and goal setting as well as their self-reflection. In fact, self-reflection appeared the crucial element in decisions to hold on to a stance or shift to another. Finally, students appeared to develop an identity with the PBL program as well as with the world of medical practice. However, attuning one's identity to the (demands of) learning environment appeared hard for students (Evensen et al. 2001).

Effects of the learning environment on students' SRL were investigated by Sungur and Tekkaya (2006). Two groups of students were tested: one group received teacher-centered instruction, while the other group was taught with PBL. Students' scores on the Motivated Strategies for Learning Questionnaire (Pintrich and de Groot 1990) were compared. PBL 
students reported higher levels of intrinsic goal orientation, task value, use of elaboration strategies, critical thinking, and metacognition (Sungur and Tekkaya 2006).

The role of self-assessment in SRL was investigated by Langendyk (2006). Third-year students in a medical PBL curriculum took a formative assessment. Students were asked to evaluate their own assessment paper as well as the paper of one of their fellow students. To that end, correct answers and grading criteria were provided. In addition, assessment papers were graded by faculty members. Relations between self- and peer-assessment and overall academic performance were examined. Low-achieving students graded themselves and their peers generously, while high-achieving students scored themselves more harshly than faculty. Peer grading of high-achieving students was, however, accurate. It was concluded that the majority of third-year students was able to judge their own performance and that of their peers accurately, although low-achieving students tended to be more inaccurate in their grading.

\section{Conclusion}

This study investigated the role of SDL in PBL and examined how SDL relates to SRL. A review of empirical studies that examined SDL and SRL in PBL environments was conducted. The first part of this study explained the concept of SDL and how it is implemented in PBL. In addition, the study aimed to establish conceptual clarity between SDL and SRL. It is argued that SDL and SRL have similarities with respect to active engagement, goal-directed behavior, metacognitive skills, and intrinsic motivation. Yet, a close examination of both concepts led to the conclusion that they cannot be used synonymously. While SRL is usually considered as a learner characteristic, SDL is both a learner characteristic and a design feature of the learning environment. Further, SDL entails more student control over the learning environment and provides a crucial role for the learner in initiating a learning task. This review also brought several conclusions to the fore.

SDL and SRL are developmental processes

First, the studies showed that SDL and SRL are developmental processes since college seniors were found to be more self-directed and self-regulated in several studies. For example, seniors engaged in study activities beyond the learning issues (van den Hurk et al. 1999). Also, seniors relied less on external guidance when deciding what to study (Dolmans and Schmidt 1994, 2000). Students' reliance on others decreased (Kivela and Kivela 2005) and they became more certain about the selection of their literature resources (Dahlgren and Dahlgren 2002). Further, Evensen (2000) ascertained the development of SDL skills during students' first semester. With respect to SRL, developmental processes were also observed (Evensen et al. 2001). The developmental nature implies that SDL and SRL can be learned by students. However, the studies indicate that this is not an easy process (Evensen et al. 2001), especially not for younger students since they need to overcome their feelings of uncertainty.

The "self" aspect is crucial

Empirical evidence was found for the importance of the "self" aspect in SDL and SRL. Studies demonstrated the importance of self-generation of learning issues (Verkoeijen et al. 2006) and showed that self-monitoring is beneficial for academic achievement (van den Hurk 2006). Self-reflection was crucial for forms of self-regulation (Evensen et al. 2001) and self- 
assessment was performed accurately by high-achieving students (Langendyk 2006). These findings emphasize the crucial controlling role of the learner and the actions that he or she initiates and undertakes.

Does PBL foster SDL or SRL? Mixed results

With respect to the question whether PBL fosters SDL and SRL, mixed results were found. Some studies gave evidence that PBL fosters SDL (Blumberg 2000; Hmelo and Lin 2000; Kivela and Kivela 2005) and SRL (Sungur and Tekkaya 2006). Students' perceptions also seem to support this conclusion (Blumberg 2000; Srinivasan et al. 2007). The study of Lohman and Finkelstein (2000) was more nuanced and concluded that PBL students scored higher on SDL but only in small and medium groups. Lloyd-Jones and Hak (2004) did not found evidence for the assumption that PBL fosters SDL. Although most studies reported positive results, the way SDL is understood and interpreted by students and teachers seems of overriding importance. A study of Moust et al. (2005) reflected on three decades of PBL at Maastricht University. The authors warn for "signs of erosion" in PBL (p. 665).

With respect to SDL, it is conjectured that not only students can experience uncertainty whether they have covered the intended course content by their self-study activities. Faculty and tutors can share this fear. In such cases, students are often provided with the core literature resources, which reassures faculty and tutors that the content will be covered. Clearly, the freedom to select and critically evaluate learning materials is completely undermined and SDL becomes impossible. Conceptual clarity of what SDL entails and guidance for both teachers and students can help PBL to bring forth self-directed learners (Miflin et al. 2000).

Acknowledgment The authors gratefully acknowledge Drs. Henk Schmidt, Cindy Hmelo-Silver, Fred Paas, and David Gijbels for their valuable comments on this paper.

Open Access This article is distributed under the terms of the Creative Commons Attribution Noncommercial License which permits any noncommercial use, distribution, and reproduction in any medium, provided the original author(s) and source are credited.

\section{References}

Ainley, M., \& Patrick, L. (2006). Measuring self-regulated learning processes through tracking patterns of student interaction with achievement activities. Educational Psychology Review, 18, 267-286. doi:10.1007/s10648006-9018-z.

Bandura, A. (1997). Self-efficacy: The exercise of control. New York: Freeman.

Barrett, T. (2005). Understanding problem-based learning. In T. Barrett, I. Mac Labhrainn, \& H. Fallon (Eds.), Handbook of enquiry and problem-based learning (pp. 13-25). Galway: CELT.

Barrows, H. S. (1984). A specific, problem-based, self-directed learning method designed to teach medical problem-solving skills, self-learning skills and enhance knowledge retention and recall. In H. G. Schmidt, \& M. L. De Volder (Eds.), Tutorials in problem-based learning. Assen: Van Gorcum.

Barrows, H. S. (1985). How to design a problem-based curriculum for preclinical years. New York: Springer.

Barrows, H. S. (1986). A taxonomy of problem-based learning methods. Medical Education, 20, 481-486.

Barrows, H. S. (1996). Problem-based learning in medicine and beyond: A brief overview. In W. H. Gijselaers (Ed.), New directions for teaching and learning (vol. Vol. 68, (pp. 3-11)). San Francisco: Jossey-Bass.

Barrows, H. S., \& Tamblyn, R. (1980). Problem-based learning: An approach to medical education. New York: Springer.

Blumberg, P. (2000). Evaluating the evidence that problem-based learners are self-directed learners: A review of the literature. In D. Evensen, \& C. E. Hmelo (Eds.), Problem-based learning: A research perspective on learning interactions (pp. 199-226). Mahwah: Erlbaum. 
Boekaerts, M. (1999). Self-regulated learning: where we are today. International Journal of Educational Research, 31, 445-457. doi:10.1016/S0883-0355(99)00014-2.

Boekaerts, M., \& Corno, L. (2005). Self-regulation in the classroom: A perspective on assessment and intervention. Applied Psychology: An International Review, 54, 199-231. doi:10.1111/j.14640597.2005.00205.x.

Boekaerts, M., \& Cascallar, E. (2006). How far have we moved toward the integration of theory and practice in self-regulation? Educational Psychology Review, 18, 199-210. doi:10.1007/s10648-006-9013-4.

Candy, P. C. (1991). Self-direction for lifelong learning. San Francisco: Jossey-Bass.

Dahlgren, M. A., \& Dahlgren, L. O. (2002). Portraits of PBL: Students' experiences of the characteristics of problem-based learning in physiotherapy, computer engineering and psychology. Instructional Science, 30, 111-127. doi:10.1023/A:1014819418051.

Dolmans, D. H. J. M., \& Schmidt, H. G. (1994). What drives the student in problem-based learning? Medical Education, 28, 372-380.

Dolmans, D. H. J. M., \& Schmidt, H. G. (2000). What directs self-directed learning in a problem-based curriculum? In D. Evensen, \& C. E. Hmelo (Eds.), Problem-based learning: A research perspective on learning interactions (pp. 251-262). Mahwah: Erlbaum.

Dornan, T., Hadfield, J., Brown, M., Boshuizen, H., \& Scherpbier, A. (2005). How can medical students learn in a self-directed way in the clinical environment? Design-based research. Medical Education, 39, 356-364. doi:10.1111/j.1365-2929.2005.02112.x.

Dornan, T., Boshuizen, H., King, N., \& Scherpbier, A. (2007). Experience-based learning: A model linking the processes and outcomes of medical students' workplace learning. Medical Education, 41, 84-91. doi:10.1111/j.1365-2929.2006.02652.x.

Entwistle, N. J., \& Peterson, E. R. (2004). Conceptions of learning and knowledge in higher education: Relationships with study behaviour and influences of learning environments. International Journal of Educational Research, 41, 407-428. doi:10.1016/j.ijer.2005.08.009.

Evensen, D. H. (2000). Observing self-directed learners in a problem-based learning context: Two case studies. In D. Evensen, \& C. E. Hmelo (Eds.), Problem-based learning: A research perspective on learning interactions (pp. 263-297). Mahwah: Erlbaum.

Evensen, D. H., Salisbury-Glennon, J. D., \& Glenn, J. (2001). A qualitative study of six medical students in a problem-based curriculum: Toward a situated model of self-regulation. Journal of Educational Psychology, 93, 659-676. doi:10.1037/0022-0663.93.4.659.

Fisher, M., King, J., \& Tague, G. (2001). Development of a self-directed learning readiness scale for nursing education. Nurse Education Today, 21, 516-525. doi:10.1054/nedt.2001.0589.

Greveson, G. C., \& Spencer, J. A. (2005). Self-directed learning-The importance of concepts and contexts. Medical Education, 39, 348-349. doi:10.1111/j.1365-2929.2005.02115.x.

Guglielmino, L. M. (1995). Self-Directed Learning Readiness Scale. Boca Raton: Florida Atlantic University.

Hmelo, C. E., \& Lin, X. (2000). Becoming self-directed learners: Strategy development in problem-based learning. In D. Evensen, \& C. E. Hmelo (Eds.), Problem-based learning: A research perspective on learning interactions (pp. 227-250). Mahwah: Erlbaum.

Hmelo-Silver, C. E. (2004). Problem-based learning: What and how do students learn? Educational Psychology Review, 16, 235-266. doi:10.1023/B:EDPR.0000034022.16470.f3.

Kivela, J., \& Kivela, R. J. (2005). Student perceptions of an embedded problem-based learning instructional approach in a hospitality undergraduate programme. International Journal of Hospitality Management, 24, 437-464. doi:10.1016/j.ijhm.2004.09.007.

Knowles, M. S. (1975). Self-directed learning: A guide for learners and teachers. New York: Association Press.

Knowles, M. S. (1990). The adult learner: A neglected species (4th ed.). Houston: Gulf Publishing.

Kreber, C. (1998). The relationship between self-directed learning, critical thinking, and psychological type, and some implications for teaching in higher education. Studies in Higher Education, 23, 71-86. doi:10.1080/03075079812331380502.

Langendyk, V. (2006). Not knowing that they do not know: Self-assessment accuracy of third-year medical students. Medical Education, 40, 173-179. doi:10.1111/j.1365-2929.2005.02372.x.

Lloyd-Jones, G., \& Hak, T. (2004). Self-directed learning and student pragmatism. Advances in Health Sciences Education, 9, 61-73. doi:10.1023/B:AHSE.0000012228.72071.1e.

Lohman, M. C., \& Finkelstein, M. (2000). Designing groups in problem-based learning to promote problemsolving skills and self-directedness. Instructional Science, 28, 291-307. doi:10.1023/A:1003927228005.

Mason, L. H. (2004). Explicit self-regulated strategy development versus reciprocal questioning: Effects on expository reading comprehension among struggling readers. Journal of Educational Psychology, 96, 283-296. doi:10.1037/0022-0663.96.2.283. 
Miflin, B. M. (2004). Adult learning, self-directed learning and problem-based learning: Deconstructing the connections. Teaching in Higher Education, 9, 43-53. doi:10.1080/1356251032000155821.

Miflin, B. M., Campbell, C. B., \& Price, D. A. (2000). A conceptual framework to guide the development of self-directed, lifelong learning in problem-based medical curricula. Medical Education, 34, 299-306. doi:10.1046/j.1365-2923.2000.00564.x.

Minnaert, A., \& Janssen, P. J. (1999). The additive effect of regulatory activities on top of intelligence in relation to academic performance in higher education. Learning and Instruction, 9, 77-91. doi:10.1016/ S0959-4752(98)00019-X.

Moust, J. H. C., van Berkel, H. J. M., \& Schmidt, H. G. (2005). Signs of erosions: Reflections of three decades of problem-based learning at Maastricht University. Higher Education, 50, 665-683. doi:10.1007/s10734-0046371-z.

Norman, G. R., \& Schmidt, H. G. (1992). The psychological basis of problem-based learning: A review of the evidence. Academic Medicine, 67, 557-565.

Paris, S. G., \& Paris, A. H. (2001). Classroom applications of research on self-regulated learning. Educational Psychologist, 36, 89-101. doi:10.1207/S15326985EP3602 4.

Pintrich, P. R. (1999). The role of motivation in promoting and sustaining self-regulated learning. International Journal of Educational Research, 31, 459-470. doi:10.1016/S0883-0355(99)00015-4.

Pintrich, P. R. (2003). Multiple goals and multiple pathways in the development of motivation and selfregulated learning. In L. Smith, C. Rogers, \& P. Tomlinson (Eds.), Development and motivation: Joint perspectives (pp. 137-155). Leicester: British Psychological Society.

Pintrich, P. R. (2004). A conceptual framework for assessing motivation and self-regulated learning in college students. Educational Psychology Review, 16, 385-407.

Pintrich, P. R., \& de Groot, E. V. (1990). Motivational and self-regulated learning components of classroom academic performance. Journal of Educational Psychology, 82, 33-40. doi:10.1037/0022-0663.82.1.33.

Savin-Baden, M., \& Major, C. H. (2004). Foundations of problem-based learning. Berkshire: SRHE \& Open University Press.

Schmidt, H. G. (1983). Problem-based learning: Rationale and description. Medical Education, 17, 11-16.

Schmidt, H. G. (2000). Assumptions underlying self-directed learning may be false. Medical Education, 34, 243-245. doi:10.1046/j.1365-2923.2000.0656a.x.

Schmidt, H. G., Vermeulen, L., \& van der Molen, H. T. (2006). Long term effects of problem-based learning: A comparison of competencies acquired by graduates of a problem-based and a conventional medical school. Medical Education, 40, 562-567. doi:10.1111/j.1365-2929.2006.02483.x.

Schmidt, H. G., Loyens, S. M. M., Van Gog, T., \& Paas, F. (2007). Problem-based learning is compatible with human cognitive architecture: Commentary on Kirschner, Sweller, and Clark (2006). Educational Psychologist, 42, 91-97.

Shanley, P. F. (2007). Leaving the "empty glass" of problem-based learning behind: New assumptions and a revised model for case study in preclinical medical education. Academic Medicine, 82, 479-485. doi:10.1097/ACM.0b013e31803eac4c.

Shin, J. H., Haynes, R. B., \& Johnston, M. E. (1993). Effect of problem-based, self-directed undergraduate education on life-long learning. Canadian Medical Education Journal, 148, 999-976.

Srinivasan, M., Wilkes, M., Stevenson, F., Nguyen, T., \& Slavin, S. (2007). Comparing problem-based learning with case-based learning: Effects of a major curricular shift at two institutions. Academic Medicine, 82, 74-82. doi:10.1097/01.ACM.0000249963.93776.aa.

Sungur, S., \& Tekkaya, C. (2006). Effects of problem-based learning and traditional instruction on selfregulated learning. The Journal of Educational Research, 99, 307-317. doi:10.3200/JOER.99.5.307-320.

van den Hurk, M. M. (2006). The relation between self-regulated strategies and individual study time, prepared participation and achievement in a problem-based curriculum. Active Learning in Higher Education, 7, 155-169. doi:10.1177/1469787406064752.

van den Hurk, M. M., Wolfhagen, I. H. A. P., Dolmans, D. J. H. M., \& van der Vleuten, C. P. M. (1999). The impact of student-generated learning issues on individual study time and academic achievement. Medical Education, 33, 808-814. doi:10.1046/j.1365-2923.1999.00403.x.

Verkoeijen, P. P. J. L., Rikers, R. M. J. P., te Winkel, W. W. R., \& van den Hurk, M. M. (2006). Do studentdefined learning issues increase quality and quantity of individual study? Advances in Health Sciences Education, 11, 337-347. doi:10.1007/s10459-006-9013-7.

Winne, P. H. (1995). Self-regulation is ubiquitous but its forms vary with knowledge. Educational Psychologist, 30, 217-221. doi:10.1207/s15326985ep3004_8.

Winne, P. H., \& Hadwin, A. F. (1998). Studying as self-regulated engagement in learning. In D. Hacker, J. Dunlosky, \& A. Graesser (Eds.), Metacognition in educational theory and practice (pp. 277-304). Hillsdale: Lawrence Erlbaum. 
Winne, P. H., \& Perry, N. E. (2000). Measuring self-regulated learning. In M. Boekaerts, P. R. Pintrich, \& M. Zeidner (Eds.), Handbook of self-regulation (pp. 531-566). San Diego: Academic.

Zimmerman, B. J. (1989). A social cognitive view of self-regulated academic learning. Journal of Educational Psychology, 81, 329-339. doi:10.1037/0022-0663.81.3.329.

Zimmerman, B. J. (1998). Developing self-fulfilling cycles of academic regulation: An analysis of exemplary instructional methods. In D. H. Schunk, \& B. J. Zimmerman (Eds.), Self-regulated learning: From teaching to self-reflexive practice (pp. 1-19). New York: Guilford.

Zimmerman, B. J. (2000). Attaining self-regulation: A social cognitive perspective. In M. Boekaerts, P. R. Pintrich, \& M. Zeidner (Eds.), Handbook of self-regulation (pp. 13-39). San Diego: Academic.

Zimmerman, B. J., \& Lebeau, R. B. (2000). A commentary on self-directed learning. In D. Evensen, \& C. E. Hmelo (Eds.),Problem-based learning: A research perspective on learning interactions (pp. 299-313). Mahwah: Erlbaum. 